\title{
Germination Behavior of Wheat (Triticum Aestivum L.) as Influenced by Polyethylene Glycol (PEG)
}

\author{
Abdullahil Baque ${ }^{1, *}$, Munmun Nahar ${ }^{1}$, Marjana Yeasmin $^{1}$, Md. Quamruzzaman ${ }^{1}$, Atiqure Rahman $^{2}$, \\ Md. Javed Azad ${ }^{3}$, Parimal Kanti Biswas ${ }^{1}$ \\ ${ }^{1}$ Department of Agronomy, Sher-e-Bangla Agricultural University, Bangladesh \\ ${ }^{2}$ Planning and Institutional Trials, Syngenta Bangladesh Ltd. Bangladesh \\ ${ }^{3}$ Department of Agricultural Extension and Information System, Sher-e-Bangla Agricultural University, Bangladesh
}

Copyright $\mathrm{C} 2016$ by authors, all rights reserved. Authors agree that this article remains permanently open access under the terms of the Creative Commons Attribution License 4.0 International License

\begin{abstract}
Pre-sowing seed treated with Polyethylene Glycol (PEG) helps to enhance the germination behavior of seed. So, a lab experiment was conducted to find out the effect of various Polyethylene Glycol (PEG) concentrations on the germination behavior of wheat. Wheat seeds of BARI Gom 27 and BARI Gom 28 were pre-soaked in $0,5,10,15$ and 20\% PEG solution and untreated seeds were served as control. Results revealed that seed priming enhanced germination percentage (GP), vigor index (VI) and germination index (GI) of wheat seed. The highest GP (95.55\%), VI (201.00) and GI (43.73) were obtained from seeds of BARI Gom 27 pre-treated with 10\% PEG solution compared to BARI Gom 28 (75.55\%, 128.71 and 27.12 of GP, VI and GI, respectively) and then decreased gradually with increasing PEG concentration. Therefore, seed priming helps to enhance the germination behavior of wheat seed.
\end{abstract}

Keywords Germination, Polyethylene Glycol, Wheat, Vigor Index

\section{Introduction}

Plants create some defense mechanism on itself during the stress condition as a result yield of crops reduce but helps to increase the seed quality [1]. Though stress has this positive impact on seed but it is not good for seed germination especially for drought stress. And for this reason seed priming is considered as a promising approach to increase stress tolerance capacity of crop plants including drought. Seed priming is the induction of a particular physiological state in plants by the treatment of natural and synthetic compounds to the seeds before germination. The physiological state in which plants are able to faster or better activate defense responses or both is called the primed state of the plant [2]. Seed priming can be accomplished through different methods such as hydro-priming (soaking in DW), osmo-priming (soaking in osmotic solutions such as PEG, potassium salts, e.g., $\mathrm{KCl}, \mathrm{K} 2 \mathrm{SO} 4)$ and plant growth inducers (CCC, Ethephon, IAA) [3, 4, 5,6].

Seed priming is also widely used to synchronize the germination of individual seeds [7]. Seed-priming technology has twofold benefits: enhanced, rapid and uniform emergence, with high vigor and better yields in vegetables and floriculture [8] and some field crops $[9,10]$. According to McDonald [11], primed seeds acquire the potential to rapidly imbibe and revive the seed metabolism thus enhancing the germination rate.

In many crops, seed germination and early seedling growth are the most sensitive stages of water limitation and the water deficit may delay the onset and reduce the rate and uniformity of germination, leading to poor crop performance and yield [12]. Therefore, the beneficial effects of priming may be more evident under unfavorable rather than favorable conditions [13]. Primed seeds usually exhibit an increased germination rate, greater germination uniformity, and at times, greater total germination percentage [9]. These attributes have practical agronomic implications, notably under adverse germination conditions [11]. Therefore, there is a strong interest in the seed industry to find suitable priming agent(s) that might be used to increase the tolerance of plants under adverse field conditions [14].

\section{Materials and Methods}

The experiment was conducted under the laboratory condition of the department of Agronomy, Sher-e-Bangla Agricultural University, Dhaka from August 2013 to February 2014. Temperature range of the laboratory during the experiment was $26.2^{\circ} \mathrm{C}-33.4{ }^{\circ} \mathrm{C}$ and the relative humidity was $56-84 \%$.

In this research work, seeds of the Wheat variety BARI Gom 27 and BARI Gom 28 collected from Bangladesh 
Agricultural Research Institute were used as planting material. Different priming chemicals such as PEG and distilled water were utilized for osmo and hydro priming. Different equipment such as growth chamber, electric balance, Petri dish, filter paper, micro pipette etc. were used for this study.

All seeds were surface sterilized with 2\% Safex solution for 5 minutes, then rinsed with sterilized water and air dried at room temperature. After that seeds were used for priming.

All priming media were prepared in distilled water and duration of soaking for hydro and osmopriming were $12 \mathrm{~h}$. After soaking seeds were air dried and placed in Petridish. For each replicate 30 seeds were placed in $12.5 \mathrm{~cm}$ Petridish on a layer of filter paper no. 102 moistened with $8 \mathrm{ml}$ of distilled water.

The experiment was conducted in Completely Randomized Design (CRD) with five replications. The first factor was the two wheat varieties viz., BARI Gom 27 (V1) and BARI Gom 28 (V2); second factor was the six priming with Polyethylene Glycol (PEG) viz., Non- primed seeds (T0) Seeds primed with water for $12 \mathrm{~h}(\mathrm{Tw})$, Seeds primed with 5\% PEG for $12 \mathrm{~h}$ (T5), Seeds primed with 10\% PEG for $12 \mathrm{~h}$ (T10), Seeds primed with $15 \%$ PEG for $12 \mathrm{~h}$ (T15), Seeds primed with $20 \%$ PEG for $12 \mathrm{~h}$ (T20). After that data collected on various parameters and mean data of germination percentage, plumule length, radical length, seedling length, vigour index, germination index and seedling dry weight were recorded and analyzed using statistical computer software MSTAT-C and mean were separated using least significance difference (LSD) at 5\% level of probability.

\section{Result and Discussion}

\subsection{Effect on Germination Percentage}

Germination percentage of wheat was influenced by various Polyethylene Glycol (PEG) concentrations (Figure 1) and there was completely significant difference between control (non primed seeds) and primed seeds. Germination percentage (GP) was affected by hydro priming and different PEG concentrations. Germination percentage (GP) increases with increasing PEG concentration up to $10 \%$ then decreases gradually with increasing PEG concentration. The highest GP $(95.55 \%)$ of BARI Gom 27 was obtained from seeds pre-treated with $10 \%$ PEG solutionwhich is $17.43 \%$ and $13.95 \%$ higher over control and osmoprimed seeds, respectively. The highest GP (75.55\%) of BARI Gom 28 was obtained from seeds pre-treated with $10 \%$ PEG solution which is $17.64 \%$ and $13.23 \%$ higher over control and osmoprimed seeds, respectively. Germination percent of BARI Gom 27 was higher compared to BARI Gom 28.

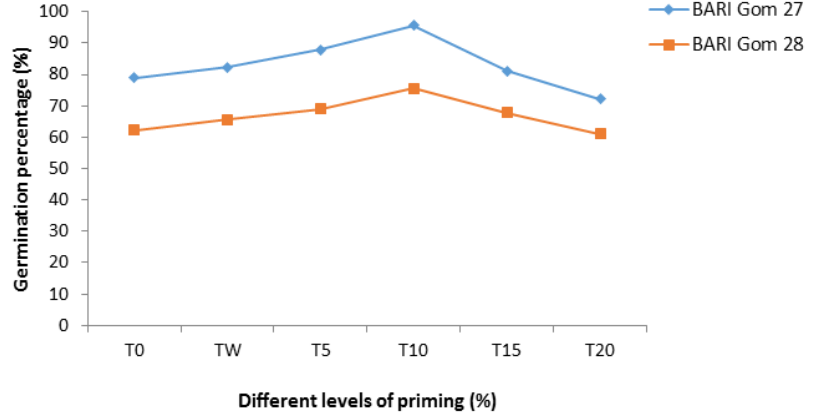

Note: T0: Non- primed seeds (Control),Tw: Seeds primed with water for 12 $\mathrm{h}$,

T5: Seeds primed with 5\% PEG for $12 \mathrm{~h}, \mathrm{~T} 10$ : Seeds primed with $10 \%$ PEG for $12 \mathrm{~h}$,

T15: Seeds primed with $15 \%$ PEG for $12 \mathrm{~h}$, T20: Seeds primed with $20 \%$ PEG for $12 \mathrm{~h}$.

Figure 1. Effect of various Polyethylene Glycol (PEG) concentrations on the germination percentage of wheat $\left(\operatorname{LSD}_{0.05}=8.973,3.443\right)$

The result of the present study corroborates with the study of previous researchers $[15,16,17,18,19]$. According to Ajouri et al. [16] priming induces a range of biochemical changes in the seed that required initiating the germination process i.e., breaking of dormancy, hydrolysis or metabolism of inhibitors, imbibition and enzymes activation. Hydropriming significantly improved germination rate [15] and is a useful technique for improving overall germination viz. tomato variety germination percentage was increased in response to hydro-priming treatment [17]. Farooq et al. [18] suggested that physiological changes produced by osmohardening enhanced the starch hydrolysis and made more sugars available for embryo growth which enhance germination. Sun et al. [19] reported that optimal priming concentrations of PEG were 20\% for Gangyou 527 (indica hybrid rice) and $10 \%-15 \%$ for Nongken 57 (conventional japonica rice). Even higher concentrations of PEG had negative effects on seed germination.

\subsection{Effect on Plumule Length (mm)}

Plumule length $(\mathrm{mm})$ of wheat was influenced by various Polyethylene Glycol (PEG) concentrations (Figure 2) and variance analysis results showed that there was significant difference between control (non primed seeds) and primed seeds. Plumule length was affected by hydro priming and different PEG concentration. Plumule length increases with increasing PEG concentration up to $10 \%$ then decreases gradually with increasing PEG concentration. The highest plumule length $(97.7 \mathrm{~mm})$ of BARI Gom 27 was obtained from seeds pre-treated with $10 \%$ PEG solution which is $27.05 \%$ and $23.57 \%$ higher over control and osmoprimed seeds, respectively. The highest plumule length $(83.20 \mathrm{~mm})$ of BARI Gom 28 was obtained from seeds pre-treated with $10 \%$ PEG solution which is $28.24 \%$ and $21.63 \%$ higher over control and osmoprimed seeds, respectively. Plumule length of BARI Gom 27 was higher compared to BARI Gom 28. 


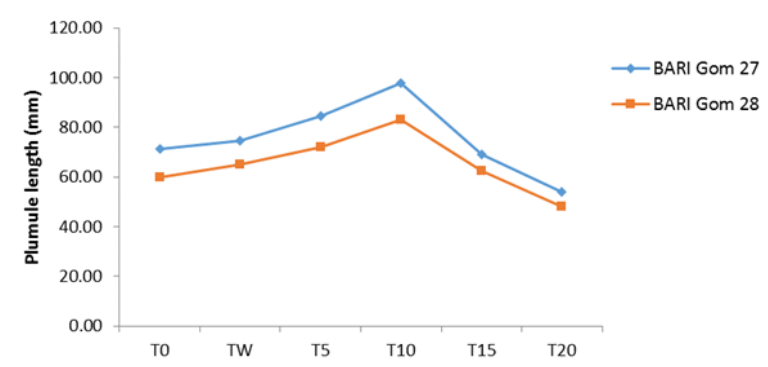

Note: T0: Non- primed seeds (Control), Tw: Seeds primed with water for 12 $\mathrm{h}$,

T5: Seeds primed with $5 \%$ PEG for $12 \mathrm{~h}$, T10: Seeds primed with $10 \%$ PEG for $12 \mathrm{~h}$,

T15: Seeds primed with $15 \%$ PEG for $12 \mathrm{~h}$, T20: Seeds primed with $20 \%$ PEG for $12 \mathrm{~h}$.

Figure 2. Effect of various Polyethylene Glycol(PEG) concentrations on the plumule length of wheat (LSD $0.05=0.5979,1.029)$

\subsection{Effect on Radical Length (mm)}

Radical length $(\mathrm{mm})$ of wheat was influenced by various Polyethylene Glycol (PEG) concentrations (Figure 3) and variance analysis results showed that there was significant difference between control (non-primed seeds) and primed seeds. Radical length was affected by hydro priming and different PEG concentrations. Radical length increases with increasing PEG concentration up to $10 \%$ then decreases gradually with increasing PEG concentration. The highest radical length $(112.7 \mathrm{~mm})$ of BARI Gom 27 was obtained from seeds pre-treated with $10 \%$ PEG solution which is $30.19 \%$ and $25.46 \%$ higher over control and osmoprimed seeds, respectively. The highest radical length $(87.17 \mathrm{~mm})$ of BARI Gom 28 was obtained from seeds pre-treated with $10 \%$ PEG solution which is $20.38 \%$ and $12.89 \%$ higher over control and osmoprimed seeds, respectively. Radical length of BARI Gom 27 was higher compared to BARI Gom 28.

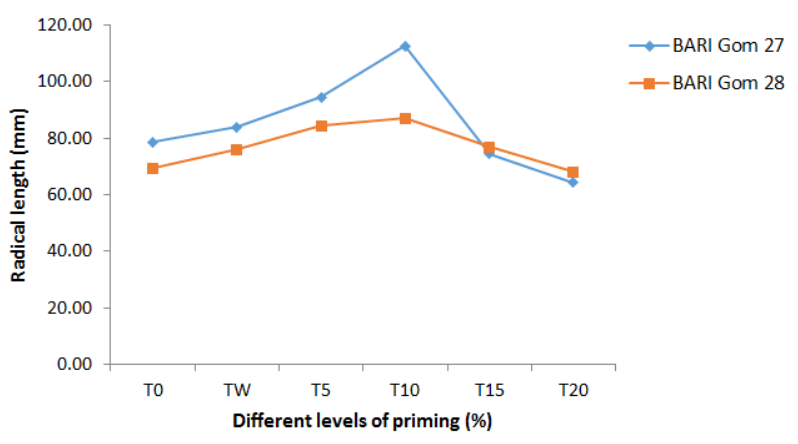

Note: T0: Non- primed seeds (Control), Tw: Seeds primed with water for 12 $\mathrm{h}$,

T5: Seeds primed with 5\% PEG for $12 \mathrm{~h}$, T10: Seeds primed with $10 \%$ PEG for $12 \mathrm{~h}$,

T15: Seeds primed with $15 \%$ PEG for $12 \mathrm{~h}$, T20: Seeds primed with $20 \%$ PEG for $12 \mathrm{~h}$

Figure 3. Effect of various Polyethylene Glycol (PEG) concentrations on the radical length of wheat $\left(\operatorname{LSD}_{0.05}=1.454,0.7846\right)$

This trend of the present results agrees to the study of previous researcher Sarwar et al. [20] who reported that root length were better when treated with water and mannitol over control.

\subsection{Effect on Seedling Length ( $\mathrm{mm})$}

Seedling length $(\mathrm{mm})$ of wheat was influenced by various Polyethylene Glycol (PEG) concentrations (Figure 4) and variance analysis results showed that there was significant difference between control (non primed seeds) and primed seeds. Seedling length was affected by hydro priming and different PEG concentrations. Seedling length increases with increasing PEG concentration up to $10 \%$ then decreases gradually with increasing PEG concentration. The highest seedling length $(210.4 \mathrm{~mm})$ of BARI Gom 27 was obtained from seeds pre-treated with $10 \%$ PEG solution which is $29.03 \%$ and $24.57 \%$ higher over control and osmoprimed seeds, respectively. The highest seedling length $(170.4 \mathrm{~mm})$ of BARI Gom 28 was obtained from seeds pre-treated with $10 \%$ PEG solution which is $24.23 \%$ and $17.19 \%$ higher over control and osmoprimed seeds, respectively. Seedling length of BARI Gom 27 was higher compared to BARI Gom 28.

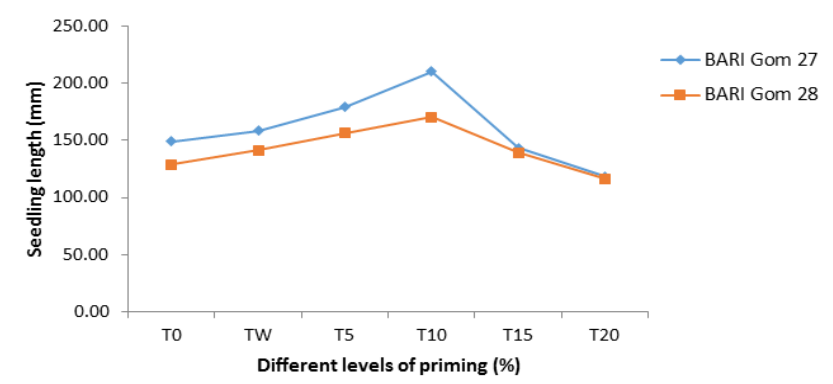

Note: T0: Non- primed seeds (Control), Tw: Seeds primed with water for 12 $\mathrm{h}$,

T5: Seeds primed with 5\% PEG for $12 \mathrm{~h}$, T10: Seeds primed with 10\% PEG for $12 \mathrm{~h}$,

T15: Seeds primed with $15 \%$ PEG for 12 h, T20: Seeds primed with $20 \%$ PEG for $12 \mathrm{~h}$

Figure 4. Effect of various Polyethylene Glycol (PEG) concentrations on the seedling length of wheat $\left(\operatorname{LSD}_{0.05}=1.926,1.422\right)$

This result is in agreement with the findings of several workers [21, 17]. Jisha et al. [21] reported that overall growth of plants was enhanced due to the seed-priming treatments. Maiti et al. [17] observed that seed priming increases seedling vigour of several vegetable crops. The priming techniques improved seedling growth of tomato and chilli although varieties showed variation in response to different treatments.

\subsection{Effect on Vigour Index (VI)}

Vigour index (VI) of wheat was influenced by various Polyethylene Glycol(PEG) concentrations (Figure 5) and variance analysis results showed that there was significant difference between control (non primed seeds) and primed seeds. Vigour index was affected by hydro priming and 
different PEG concentrations. Vigour index increases with increasing PEG concentration up to $10 \%$ then decreases gradually with increasing PEG concentration. The highest vigour index (201) was obtained from seeds of BARI Gom 27 pre-treated with $10 \%$ PEG solution compared to BARI Gom 28 (128.71). The highest vigour index of BARI Gom 27 is $41.44 \%$ and $37.07 \%$ and of BARI Gom 28 is $37.59 \%$ and $28.16 \%$ higher over control and osmoprimed seeds, respectively.

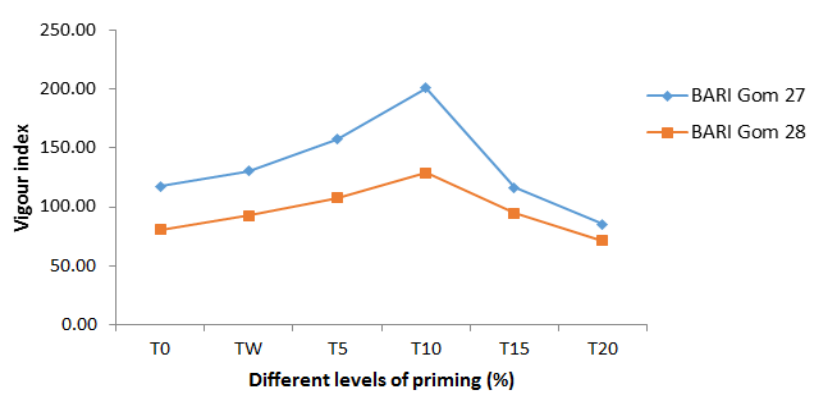

Note: T0: Non- primed seeds (Control),Tw: Seeds primed with water for 12 $\mathrm{h}$,

T5: Seeds primed with 5\% PEG for $12 \mathrm{~h}, \mathrm{~T} 10$ : Seeds primed with $10 \%$ PEG for $12 \mathrm{~h}$,

T15: Seeds primed with $15 \%$ PEG for $12 \mathrm{~h}$, T20: Seeds primed with $20 \%$ PEG for $12 \mathrm{~h}$

Figure 5. Effect of various Polyethylene Glycol(PEG) concentrations on the vigour index of wheat $\left(\operatorname{LSD}_{0.05}=12.88,5.07\right)$

This result is consistent with many scientists Maiti et al. [17]; Maiti et al. [22]. Seed priming increases seedling vigour of several vegetable crops [17] and with respect to sponge gourd, osmo-priming increased seedling vigor [22].

\subsection{Effect on Germination Index(GI)}

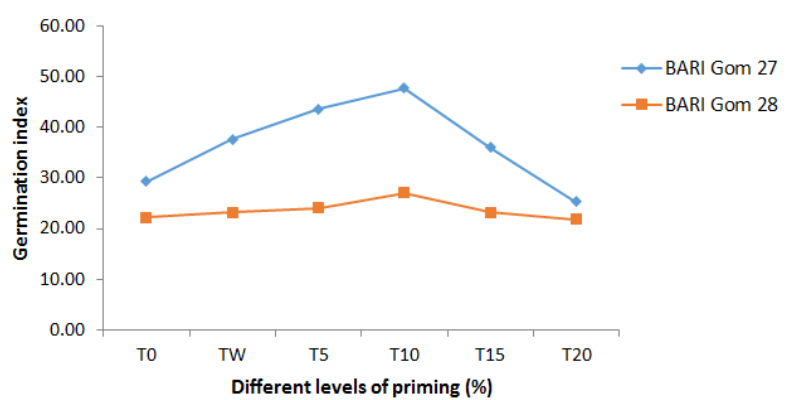

Note: T0: Non- primed seeds (Control),Tw: Seeds primed with water for 12 h,

T5: Seeds primed with 5\% PEG for $12 \mathrm{~h}$, T10: Seeds primed with $10 \%$ PEG for $12 \mathrm{~h}$

T15: Seeds primed with $15 \%$ PEG for $12 \mathrm{~h}$, T20: Seeds primed with $20 \%$ PEG for $12 \mathrm{~h}$.

Figure 6. Effect of various Polyethylene Glycol(PEG) concentrations on the germination index of wheat $\left(\mathrm{LSD}_{0.05}=3.182,1.163\right)$

Germination index (GI) of wheat was influenced by various Polyethylene Glycol(PEG) concentrations (Figure 6) and variance analysis results showed that there was significant difference between control (non primed seeds) and primed seeds. Germination index was affected by hydro priming and different PEG concentration. Germination index increases with increasing PEG concentration up to $10 \%$ then decreases gradually with increasing PEG concentrations. The highest germination index (47.73) was obtained from seeds of BARI Gom 27 pre-treated with 10\% PEG solution compared to BARI Gom 28 (27.12). The highest germination index of BARI Gom 27 is $38.63 \%$ and $21.12 \%$ and of BARI Gom 28 is $17.95 \%$ and $14.42 \%$ higher over control and osmoprimed seeds, respectively.

This result is in agreement with the findings of Huns and Sung [23] who reported that seed priming resulted anti-oxidant increment as glutathione and ascorbate in seed. These enzymes make more germination speed via reduction of lipid per-oxidation activity.

\subsection{Effect on Seedling Dry Weight (g)}

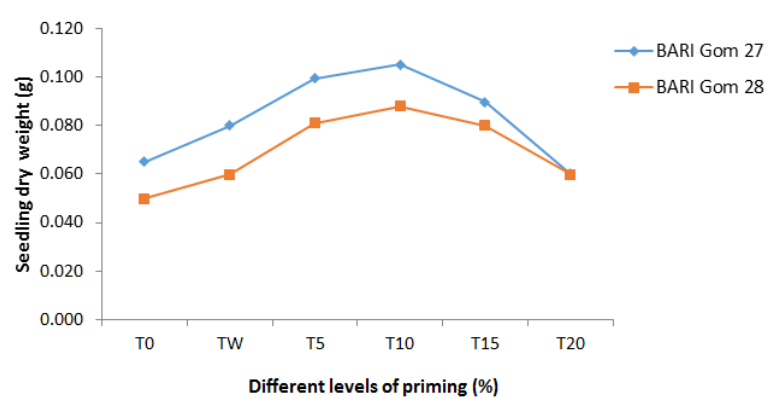

Note: T0: Non- primed seeds (Control),Tw: Seeds primed with water for 12

T5: Seeds primed with 5\% PEG for $12 \mathrm{~h}$, T10: Seeds primed with $10 \%$ PEG for $12 \mathrm{~h}$,

T15: Seeds primed with $15 \%$ PEG for 12 h, T20: Seeds primed with $20 \%$ PEG for $12 \mathrm{~h}$.

Figure 7. Effectofvarious Polyethylene Glycol(PEG) concentrations on the seedling dry weight of wheat (LSD ${ }_{0.05}=0.05753,0.05131$ )

Dry weight $(\mathrm{g})$ of wheat was influenced by various Polyethylene Glycol(PEG) concentrations (Figure 7) and variance analysis results showed that there was no significant difference between control (non primed seeds) and primed seeds. Seedling dry weight was affected by hydro priming and different PEG concentration. Seedling dry weight increases with increasing PEG concentration up to $10 \%$ then decreases gradually with increasing PEG concentration. The highest seedling dry weight $(0.105 \mathrm{~g})$ of BARI Gom 27 was obtained from seeds pre-treated with 10\% PEG solution which is $38.11 \%$ and $23.90 \%$ higher over control and osmoprimed seeds, respectively. The highest seedling dry weight $(0.088 \mathrm{~g})$ of BARI Gom 28 was obtained from seeds pre-treated with $10 \%$ PEG solution which is $43.18 \%$ and $31.81 \%$ higher over control and osmoprimed seeds, respectively. Seedling dry weight of BARI Gom 27 was higher compared to BARI Gom 28.

The result of the present study is also supported by the result of previous researchers [24, 15, 20]. Khalil et al. [24] observed that dry matter yield increased with each increment 
of priming. Ghassemi-Golezani et al. [15] showed that hydro-priming significantly improved root weights and Sarwar et al. [20] reported that root length and biomass of roots and shoots were better when treated with water and mannitol.

\section{Conclusions}

The present investigation showed that seed treated with Polyethylene Glycol (PEG) has a positive effect on germination behavior on wheat seed. Wheat seeds of BARI Gom 27 and BARI Gom 28 were pre-soaked in 0, 5, 10, 15 and $20 \%$ PEG solution and untreated seeds were served as control. Results revealed that all the characters viz., germination percentage (GP), plumule length, radical length, seedling length, vigor index (VI) and germination index (GI) were significantly influenced by various PEG concentrations except seedling dry weight for both varieties. All the parameters of both varieties gave the best results when seeds treated with $10 \%$ PEG solution compared to nonprimed and hydroprimed seeds and decreased gradually with increasing PEG concentration. The highest germination percentage, plumule length, radical length, seedling length, vigor index, germination index and seedling dry weight were obtained from seeds of BARI Gom 27 pre-treated with 10\% PEG solution compared to BARI Gom 28. So, it can be concluded that seed treated with Polyethylene Glycol (PEG) helps to increase the germination behavior on wheat seed.

\section{REFERENCES}

[1] Quamruzzaman, M., Ullah, M. J., Rahman, M. J., Chakraborty, R., Rahman, M. M., \& Rasul, M. G. (2016). Organoleptic assessment of Groundnut (Arachis hypogaea L.) as influenced by boron and artificial lightening at night. World J. Agric. Sci., 12(1): 01-06.

[2] Beckers, G.J.M. and Conrath, U. (2007). Priming for stress resistance: from the lab to the field. Curr Opin Plant Biol., 10: 425-431

[3] Capron, I., Corbineua, F., Dacher, F., Job, C., Come, D. and Job, D. (2000). Sugar beet seed priming: Effects of priming conditions on germination, solubilization of 11-s globulin and accumulation of LEA proteins. Seed Sci. Res., 10: 243-254.

[4] Chiu, K. Y., Chen, C. L. and Sung, J. M. (2002). Effect of priming temperature on storability of primed sh-2 sweet corn seed. Crop Sci., 42: 1996-2003.

[5] Harris, D., Joshi, A., Khan, P. A., Gothakar, P. and Sodhi, P. S. (1999). On-farm seed priming in semi-arid agriculture: Development and evaluation in corn, rice and Chickpea in India using participatory method. Expt. Agric., 35: 15-29.

[6] Chivasa, W., Harris, D., Chiduza, C. and Nymudeza, P. (1998). Agronomic practices, major crops and farmer's perceptions of good stand establishment in musikavanhu. J. Appl. Sci., 4: 109-125.
[7] Taylor, A.G. and Harman, G.E. (1990). Concepts and technologies of selected seed treatments. Ann. Rev. Phytopathol., 28: 321-329.

[8] Bruggink, G.T., Ooms, J.J.J. and Vander, T. P. (1999). Induction of longevity in primed seeds. Seed Sci Res., 9: 49-53.

[9] Basra, S.M.A., Farooq, M. and Tabassum, R. (2005). Physiological and biochemical aspects of seed vigour enhancement treatments in fine rice (Oryza sativa L.). Seed Sci Technol., 33: 623-628.

[10] Kaur, S., Gupta, A.K. and Kaur, N. (2005). Seed priming increases crop yield possibly by modulating enzymes of sucrose metabolism in chickpea. J. Agron. Crop. Sci., 19: 81-87.

[11] McDonald, M.B. (2000). Seed priming. In: Black M, Bewley, J.D. (eds) Seed technology and its biological basis. Sheffield Academic Press, Sheffield, pp 287-325.

[12] Demir, A.O., Goksoy, A.T., Buyukcangaz, H., Turan, Z.M. and Koksal, E.S. (2006). Deficit irrigation of sunflower (Helianthus annuus L.) in a sub-humid climate. Irrig Sci., 24: 279-289.

[13] Parera, C.A. and Cantliffe, D.J. (1994). Presowing seed priming. Hortic Rev., 16: 109-114.

[14] Job, D., Capron, I., Job, C., Dacher, F., Corbineau, F. and Come, D. (2000). Identification of germination-specific protein markers and their use in seed priming technology. In: Black M, Bradford, K.J. and Vazguez-Ramos, J. (eds) Seed biology: advances and applications. CAB International, Wallingford, pp. 449-459.

[15] Ghassemi-Golezani, K., Aliloo, A.A., Valizadeh, M. and Moghaddam, M. (2008a). Effects of Hydro and Osmo-Priming on Seed Germination and Field Emergence of Lentil (Lens culinaris Medik.). Not. Bot. Hort. Agrobot. Cluj., 36(1): 29-33.

[16] Ajouri, A., Haben, A. and Becker, M. (2004). Seed priming enhances germination and seedling growth of barley under conditions of $\mathrm{P}$ and $\mathrm{Zn}$ deficiency. J. Plant Nut. Soil Sci., 167: 630-636.

[17] Maiti, R., Rajkumar, D., Jagan, M. and Pramanik, K. (2013). Effect of Seed Priming on Seedling Vigour and Yield of Tomato and Chilli. Intt. J. Bio-res. Stress Manag., 4(2): 119-125.

[18] Farooq, M., Barsa, S.M.A. and Wahid, A. (2006). Priming of field-sown rice seed enhances germination, seedling establishment, allometry and yield. Plant Growth Regul., 49(2):285-294

[19] Sun, Y., Sun, Y., Wang, M., Li, X., Guo, X. and Hu, R. (2010). Effects of seed priming on germination and seedling growth under water stress in rice. Acta Agronomica Sinica., 36(11): 1931-1940.

[20] Sarwar, N., Yousaf, S. and Jamil, F. (2006). Induction of salt tolerance in chickpea by using simple and safe chemicals. Pak. J. Bot., 38(2): 325-329.

[21] Jisha, K. C., Vijayakumari, K. and Puthur, J. T. (2013). Seed priming for abiotic stress tolerance: an overview. Acta. Physiol. Plant., 35: 1381-1396. 
[22] Maiti, R.K., Vidyasagar, P., Rajkumar, D., Ramaswamy, A. and Rodriguez, H.G. (2011). Seed Priming Improves Seedling Vigor and Yield of few Vegetable Crops. IJbSM., 2(1): 125-130.

[23] Huns, Y. H. and Sung, J. M. (1997). Biochemical activities associated with priming of sweet corn seeds to improve vigor.
Seed Sci. Technol., 21: 97-105.

[24] Khalil, S.K., Khan, S., Rahman, A., Khan, A.Z., Khalil, I.H., Amanullah, Wahab, S., Mohammad, F., Nigar, S., Zubair, M., Parveen, S. and Khan, A. (2010). Seed priming and phosphorus application enhance phenology and dry matter production of wheat. Pak. J. Bot., 42(3): 1849-1856. 